\title{
Study the Response of Bubbled Wide Reinforced Concrete Beams with Different Shear Steel Plate Spacing
}

\author{
Amer M. Ibrahim ${ }^{1}$, Mohammed J. Hamood ${ }^{2}$, Ahmed A. Mansor ${ }^{3}$ \\ ${ }^{1}$ professor, ${ }^{3}$ Lecturer, Department of Civil Engineering, Engineering College, University of Daiyla, \\ ${ }^{2}$ Assistant professor, Department of Building \& Construction Engineering, University of \\ Technology \\ aamansor2003@yahoo.com
}

\begin{abstract}
This paper presents an experimental investigation on the behavior of bubbled wide reinforced concrete beams with different shear steel plate spacing. Four specimens with the dimensions of $215 \times 560 \times 1800 \mathrm{~mm}$ are investigated. The variables studied in this work is using the $10 \mathrm{~mm}$ stirrups with $125 \mathrm{~mm}$ spacing and $3 \mathrm{~mm}$ thickness steel plate with spacing 125, 166 and 250mm instead of reinforcing stirrups. Shear steel plates is good alternative for replacing the stirrups and gives increasing in yield and ultimate loads with $17 \%$ and $18 \%$ respectively and decreasing the deflection by $8 \%$ at yield and $12 \%$ at ultimate. Moreover decrease the strain in longitudinal reinforcement by $8 \%$ at yield and $24 \%$ at ultimate, and reduced the total weight by $2.7 \%$. By increasing the spacing of shear steel plate by $33 \%$ and $100 \%$, the results showed that the yield load reduced to $3 \%$ and $4 \%$ respectively, but the deflection was increased with $37 \%$ and $20 \%$ (at yield). The strain in interior legs is more than the strain in exterior legs by $189 \%$, $142 \%$ and $52 \%$ at yield for spacing 125, 166 and 250mm respectively. ACI 318-14 [1] and EC 2 [2] codes give a predicted deflection more than the experimental deflection by $26 \%$ and $30 \%$ on average respectively.
\end{abstract}

Keywords: Reinforced Concrete; Wide Beams Stirrups; Shear Steel Plate; Bubbles; Spacing.

Paper History: Received: (14/2/2016), Accepted: (5/4/2016)

\section{Introduction}

The use of wide concrete beams in structural framing systems has improved in latest years. This is an alteration responds to the necessity for inexpensive keys which reduce structural high and building complexities. For example, engineers of new high-rise buildings are frequently tasked with conveying column loads from the tower portion above required columnfree spaces in the pedestal or parking areas below. Wide beams may provide suitable cross-sectional areas to do the required ability in a shallower depth than a system of slenderer beams at a parallel spacing in the plan.

Adam S. Lubell, et. al [3], carried out an experimental study to investigate the shear behaviour of the wide beams and thick slabs as well as the influence of member width. In their study they tested five specimens of normal strength concrete with a nominal thickness of $470 \mathrm{~mm}$ and varied in width from 250 to 3005 $\mathrm{mm}$ with $2900 \mathrm{~mm}$ length. The study demonstrated that the failure shear stresses of narrow beams, wide beams, and slabs are all very similar.

Adam S. Lubell, et. al [4], investigated the influence of the shear reinforcement spacing on the one-way shear capacity of wide reinforced concrete members. A series of 13 normal strength concrete specimens were designed and tested. Shear reinforcement spacing was a primary test variable. The specimens contained shear reinforcement ratios close to (ACI 318-11) minimum requirements [5]. It was concluded that the effectiveness of the shear reinforcement decreases as the spacing of web reinforcement legs across the width of a member increases, the use of few shear reinforcement legs, even when widely spaced up to a distance of approximately $2 \mathrm{~d}$, has been shown to decrease the brittleness of the failure mode compared with a geometrically similar member without web reinforcement. To ensure that the shear capacity of all members with shear reinforcement are adequate when designed according to ACI 318-11, the study recommended that the transverse spacing of web reinforcement should be limited to the lesser of both the effective member depth and $600 \mathrm{~mm}$

Mohamed M. Hanafy [6], investigated the contribution of web shear reinforcement to shear strength of wide beams and the test results clearly demonstrate the significance of the web reinforcement in improving the shear capacity the ductility of the wide beams which is consistent with the recognized international codes and standards provisions. 
Amer M. Ibrahim [7], investigates the effect of steel plates on shear strength of wide reinforced concrete beams. All beams have the same dimensions, length of (1800) $\mathrm{mm}$, a width of ( 560) $\mathrm{mm}$, height of (215) $\mathrm{mm}$ and same flexural reinforcement with steel ratio of 0.0025 . They are designed to fail in shear. The study shows that the contribution of vertical steel plates to the shear capacity was significant and directly proportional to the existence and direction of the steel plates. The increase in the shear capacity ranged from $9.52 \%$ to $47.62 \%$ for the range of the tested beams compared with the control beam.

\section{The Signifigance of the Reaserch}

The study focuses on behavior of bubbled wide reinforced concrete beams using shear steel plate with different spacing. This technic treats the crowd of stirrups in wide concrete beam because the shear component provided by concrete is very small compared with high depth concrete beams. Also this study is an attempt to reduce the weight of concrete wide beam and study the effect that to: deflection, strain and crack patterns. This system consists of hollow plastic spheres cast into concrete to create a grid of void formers inside the wide beam. Indeed no design code of practice has specified design recommendation for such system.

\section{Details of the Exprimental Tests}

Out line of Program

The experimental program consisted of four beams with nominal compressive strength of $f_{c}^{\prime}=33 \mathrm{MPa}$ (Self Compacting Concrete SCC) and each tested in a four-point loading arrangement. All beams were constructed in the laboratory of the Engineering College of Diyala University. All beams were $560 \mathrm{~mm}$ wide, $215 \mathrm{~mm}$ deep, $1800 \mathrm{~mm}$ long and were tested at a shear span of $600 \mathrm{~mm}$. This gives a shear span-depth ratio $(\mathrm{a} / \mathrm{d})$ equal to 3.56 . The longitudinal steel reinforcement ratio was $\rho=2.1 \%$, with $16 \mathrm{~mm}$ diameter and using $10 \mathrm{~mm}$ diameter in compression reinforcement with $415 \mathrm{MPa}$ and $397 \mathrm{MPa}$ yield strength respectively.

All the specimens were reinforced with identical longitudinal steel bars. The specimens consist of four wide beams one reference with shear steel reinforcing (stirrups) (WBBS), and three with shear steel plate have equivalent cross sectional area for stirrups at mid legs height and having circular opening $3 \mathrm{~mm}$ thickness. The spacing between stirrups is 125 $\mathrm{mm}$ and it was $(125,166$ and $250 \mathrm{~mm})$ for shear steel plate (WBBP3-1, WBBP3-2 and WBBP3-3) and the yield strength of shear steel plate is $210 \mathrm{MPa}$. The bubbles are divided into two main groups one in the left side of left concentrated load and the other in the right side of second concentrated load. Every group consists of three rows and the row contains five bubbles. The clear distance between the every bubble in long direction $40 \mathrm{~mm}$ for stirrups specimen WBBS but it was $40 \mathrm{~mm}$, 78mm, and 48mm for WBBP3-1, WBBP3-2 and WBBP3-3 respectively, and the clear distance in transfer direction is $21 \mathrm{~mm}$ for all specimens. The different spacing of bubbles in long direction was setting as a result of the different spacing of shear steel plate.

Typical concrete dimensions and reinforcement details of the tested specimens are illustrated in Figure 1. The placements of bubbles, longitudinal reinforcement, shear steel plate and mold specimen are shown in Figure 2.

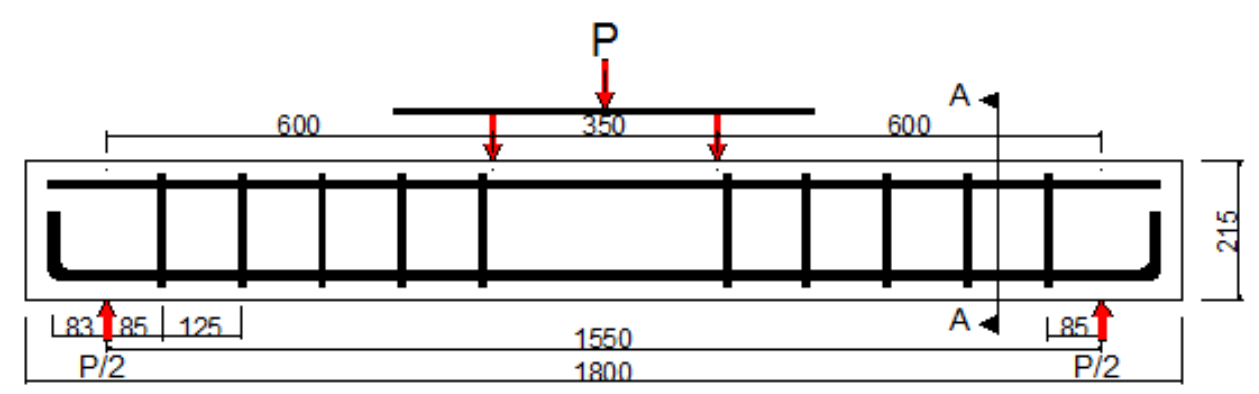

All dimensions in $\mathrm{mm}$

\section{A- Loading details}




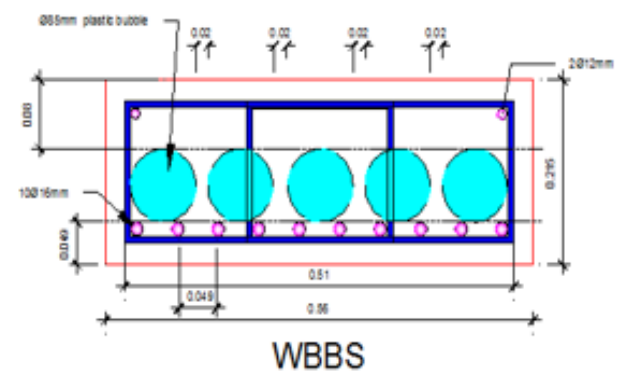

B- Section A-A for stirrups

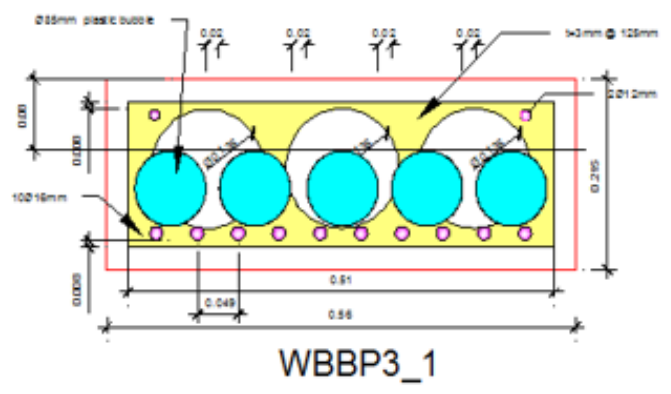

C- Section A-A for plates

Figure 1 A-Loading details, B-Section A-A for stirrups, C-Section A-A for plates

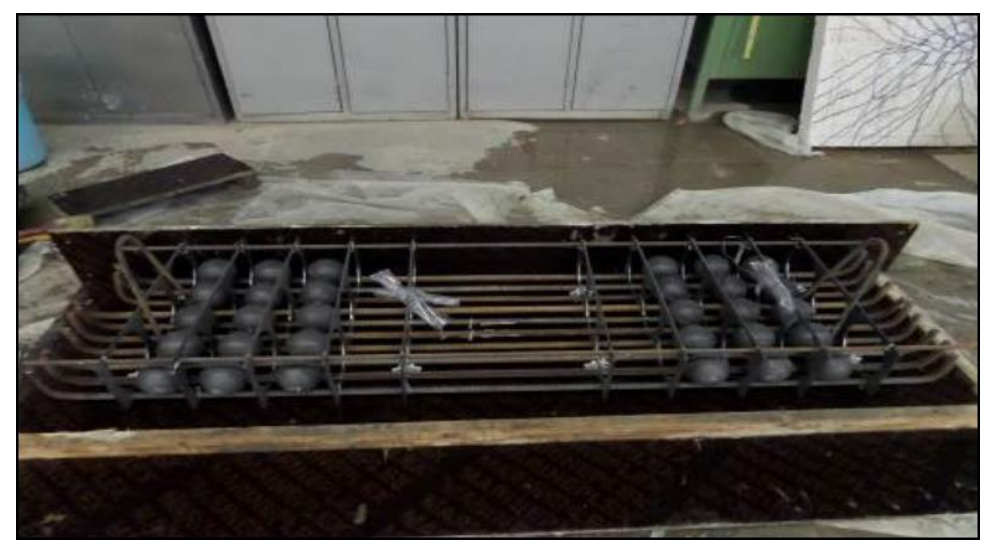

Figure 2: Peparation the mold specimen and placing the reiforcement

Tested Method and Measurments

All beams were tested under simply supported condition over a span $1.8 \mathrm{~m}$ with their tension faces uppermost as shown in Figure 1 For all beams, the first crack load, deflection under loading point, steel plate strains, yield and ultimate load were measured.

\section{Test Results}

The strength characteristics of all specimens (f'c, yield ultimate load and deflection, at yield and ultimate loads also the values of ductility) were tabulated in Table 1. Great care was taken in marking the load at which the first crack formed. The experimental values of the cracking loads were obtained from loaddeflection diagrams.

\subsection{Load Deflection Relationships}

Table 1 shows the values of deflection at yield and ultimate load that were obtained from load-deflection diagrams. It can be seen from Table 1 that the deflection at yield was increased in specimens that used the shear steel plate with $17 \%, 14 \%$ and $14 \%$ for specimens WBBP3-1, WBBP3-2 and WBBP3-3 respectively; this is obvious, due to the regular gradation increasing of yielding load. This increasing of deflection was clear in ultimate load for the specimens WBBP3-2 and WBBP3-3 when it compared with the WBBS specimen by $39 \%$ and $11 \%$ respectively but it decrease by $12 \%$ for WBBP3- 1 . For the three specimens WBBP3-1, WBBP3-2 and WBBP33 , it can be seen from Table 1 that by increasing the spacing of shears steel plate by $33 \%$ and $100 \%$, that the deflection at yield was increased with $37 \%$ and $20 \%$ respectively this is obvious, due to increasing of shear steel plate spacing. This increasing of deflection was clear at ultimate load for the specimens WBBP3-2 and WBBP3-3 when comparing with the WBBP3-1 specimen by $59 \%$ and $27 \%$ respectively, as a result of increasing of spacing of shear steel plate. Figure 3 shows the load- deflection curves for the specimens. It can be seen that the deflection at yield were close between all specimens, but the behaviour is different at ultimate load corresponding to decrease of ultimate load. Also it can be seen that the WBBP3-2 specimen is more ductile compared with the other specimens. 
Table 1 Strength characteristics of tested specimens

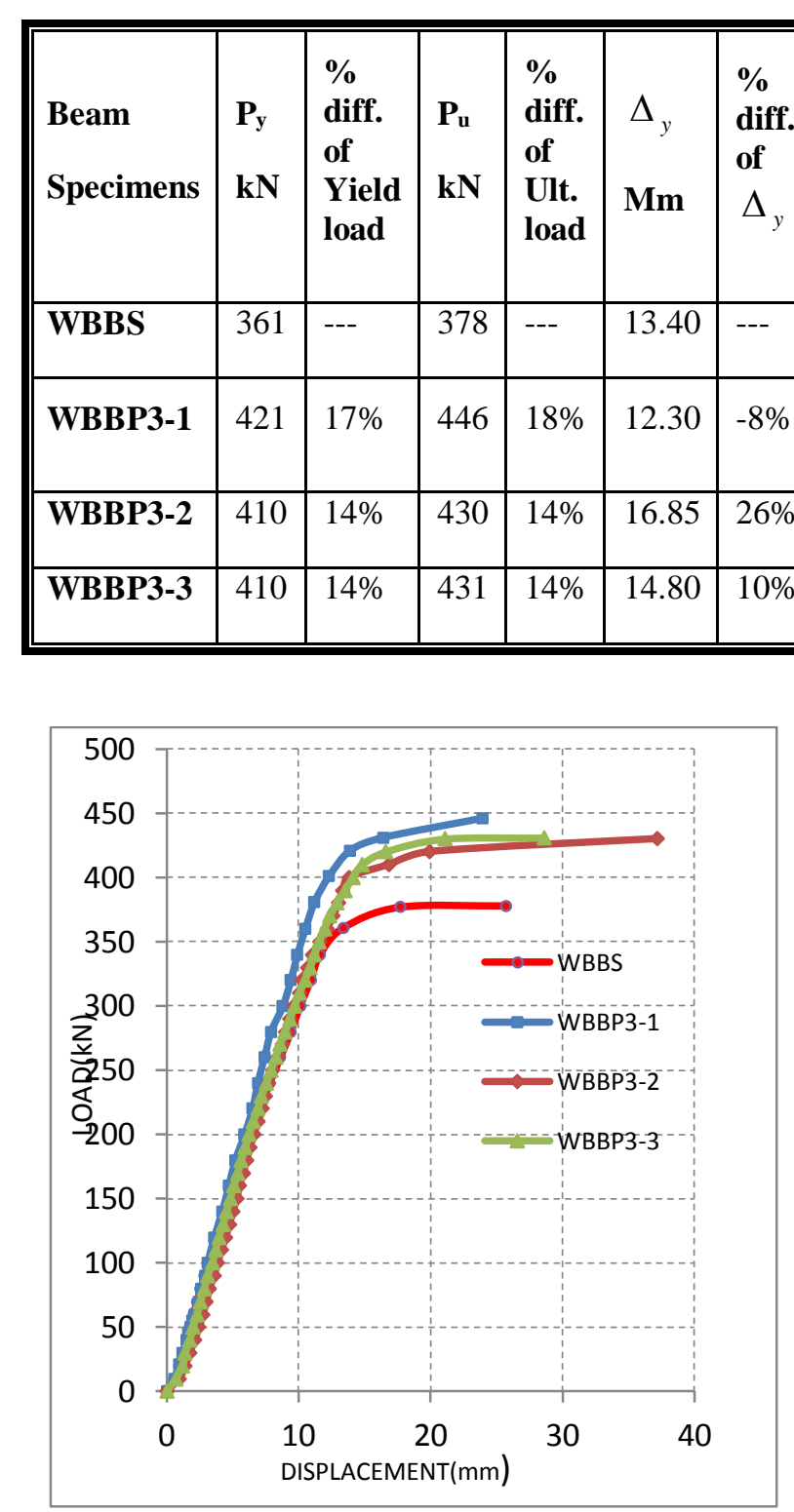

Figure 3: Load-deflection curves of specimens

\subsection{Comparison the Deflection Predicted by ACI 318-14 [1] and EC 2 [2] codes}

Table 2 shows the values of deflection at service load (assume 60\% from the ultimate load) obtained from load-deflection diagrams, also the analytical results of all specimens computing by ACI 318-14 [1] and EC 2 [2] codes at service load were presented in Table 2 , it can be seen that, the predicted deflection of wide beams calculated by ACI 318-14 [1] (as per to equation 1) and EC 2 [2] (as per to Equations 2,3,4,5, and 6)codes computed by Equation 1 and 2) were less than the experimental deflection by $26 \%$ and $30 \%$ on average respectively.

$$
\begin{aligned}
& \Delta_{\max }=\left(\frac{P . a\left(3 L^{2}-4 a^{2}\right)}{48 E_{c} I_{\text {effective }}}\right) \\
& \xi=1-0.5\left(\frac{M_{c r}}{M_{a}}\right)^{2}
\end{aligned}
$$

$\frac{1}{r_{n}}=\xi\left(\frac{M_{Q P}}{E I_{c}}\right)+(1-\xi)\left(\frac{M_{Q P}}{E I_{u}}\right)$

$\frac{1}{r_{t, Q P}}=\left(\frac{1}{r_{n}}\right)+\left(\frac{1}{r_{c s}}\right)$

$\delta_{Q P}=k l^{2} \frac{1}{r_{t, Q P}}$

$$
K,=\left(0.125-\frac{(a / l)^{2}}{6}\right)
$$

It can be explained this increasing in experimental deflection because the dial gauge was recorded the deflection in center of wide beams in longitude and transferred directions and not consider the deflections at edges for centre of beam. This case attributed to SaintVenant's principle. Saint- Venant's states that in a body under the action of a system of forces which are applied in a limited region of its boundary, the stresses and strains induced by those forces in another region of the body, located at a large distance from the region where the forces are applied, do not depend on the particular way the forces are applied, but only on their resultant. This large distance may be considered, in most cases, as the largest dimension of the region where the forces are applied [8]. From the other hand, the predicted 
deflection of wide beams as per ACI 318-14

[1] and EC 2 [2] codes, take all cross section of concrete without any subtract of volume of concrete displaced by hollow bubbles.

Table 2 Experimental deflection comparing with deflection computing by of ACI 318-14 [1] and

EC 2 [2] cods at service load

\begin{tabular}{|c|c|c|c|c|c|}
\hline \multirow{4}{*}{$\begin{array}{l}\text { Beam } \\
\text { Specimens }\end{array}$} & \multicolumn{5}{|c|}{ Deflection at Service Load, $\Delta_{s}(\mathbf{m m})$} \\
\hline & \multirow{3}{*}{$\begin{array}{l}\text { Measured } \\
(\mathrm{mm})\end{array}$} & \multicolumn{4}{|c|}{ Predicted } \\
\hline & & \multicolumn{2}{|c|}{ ACI 318M-14 } & \multicolumn{2}{|l|}{ EC 2} \\
\hline & & & \% Difference & & \% Difference \\
\hline WBBS & 3.6 & 2.60 & -27.64 & 2.51 & -30.27 \\
\hline WBBP3-1 & 3.7 & 3.07 & -16.81 & 2.90 & -21.62 \\
\hline WBBP3-2 & 4.5 & 3.00 & -33.27 & 2.81 & -37.55 \\
\hline WBBP3-3 & 4.1 & 3.00 & -26.70 & 2.86 & -30.24 \\
\hline
\end{tabular}

4.3 Strain Characteristics in Longitudinal Reinforcement and Compression Face of Concrete
Table 3 shows the values of strain in middle of longitudinal reinforcement bar and on parallel place of concrete face (in compression) at crack, yield and ultimate load that were obtained from strain gauge connected to data logger.

Table 3 Strain characteristics in longitudinal reinforcement and concrete of specimens

\begin{tabular}{||l|l|l|l|l|l|l|l|l||}
\hline \multirow{2}{*}{$\begin{array}{l}\text { Speam } \\
\text { Specimens }\end{array}$} & \multicolumn{3}{|l|}{ Longitudinal Reinforcement } & \multicolumn{3}{l||}{ Concrete (Compression) } \\
\cline { 2 - 10 } & $\varepsilon_{y}$ & $\begin{array}{l}\text { \% diff. } \\
\text { of } \varepsilon_{y}\end{array}$ & $\begin{array}{l}\varepsilon_{u} \\
\times 10^{-3}\end{array}$ & $\begin{array}{l}\text { \% diff. } \\
\text { of } \varepsilon_{u}\end{array}$ & $\begin{array}{l}\varepsilon_{y} \\
\times 10^{-3}\end{array}$ & $\begin{array}{l}\text { \% diff. } \\
\text { of } \varepsilon_{y}\end{array}$ & $\begin{array}{l}\varepsilon_{u} \\
\times 10^{-3}\end{array}$ & $\begin{array}{l}\% \text { diff. } \\
\text { of } \varepsilon_{u}\end{array}$ \\
\hline WBBS & 2.97 & --- & 4.78 & --- & -1.59 & --- & -2.94 & --- \\
\hline WBBP3-1 & 2.67 & $-10 \%$ & 3.61 & $-24 \%$ & -1.92 & $21 \%$ & -2.95 & $0.3 \%$ \\
\hline WBB3-2 & 2.47 & $-17 \%$ & 2.80 & $-41 \%$ & -2.43 & $53 \%$ & -4.00 & $36 \%$ \\
\hline WBBP3-3 & 2.16 & $-27 \%$ & 3.02 & $-37 \%$ & -1.84 & $16 \%$ & -2.84 & $-3.4 \%$ \\
\hline
\end{tabular}

\subsection{1- Strain in Longitudinal Reinforcement}

It can be seen from Table 2 that the strain in longitudinal reinforcing at yield and ultimate loads, is regular gradation decreasing in specimens WBBP3-1, WBBP3-2 and WBBP33 that used the shear steel plate with $10 \%, 17 \%$ and $27 \%$ (at yield) and by $24 \%, 41 \%$ and $37 \%$ (at ultimate) respectively with respect to control beam WBBS. By increasing the spacing of shear steel plate by $33 \%$ and $100 \%$, it can be seen from Table 2 that the strain in longitudinal reinforcement at yield and ultimate loads is decreased by $7.7 \%$ and $19 \%$ (at yield), and by $22 \%$ and $16 \%$ (at ultimate) for the specimens WBBP3-2 and WBBP3-3 respectively compared with WBBP3-1 specimen, the decreasing in strain at yield and ultimate loads may be as a result of decreasing of yield and ultimate loads of WBBP3-2 and WBBP3-3. 


\subsection{2- Strain in Compression Face of Concrete}

Based on Table 2, the strain in compression face of concrete (at middle top face of specimens) is increased for the specimen WBBP3-1 WBP3-2 and WBP3-3 compared with WBBS at yield load by $21 \%, 53 \%$ and $16 \%$. By increase the spacing of shear steel plate by $33 \%$ and $100 \%$, the strain in compression face of concrete (at middle top

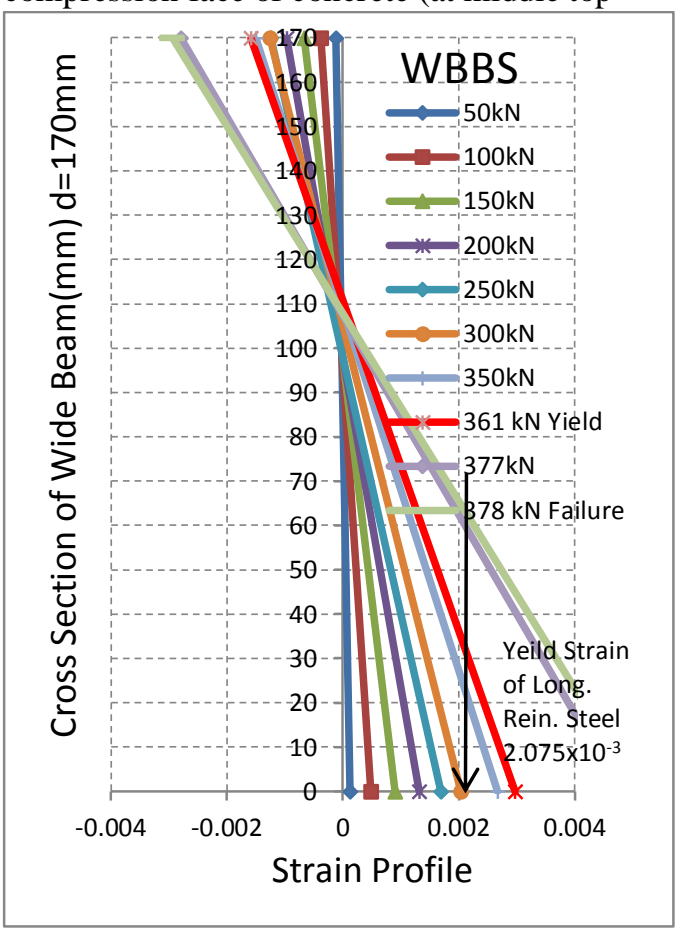

Figure 4: Strain profile of WBBS specimen

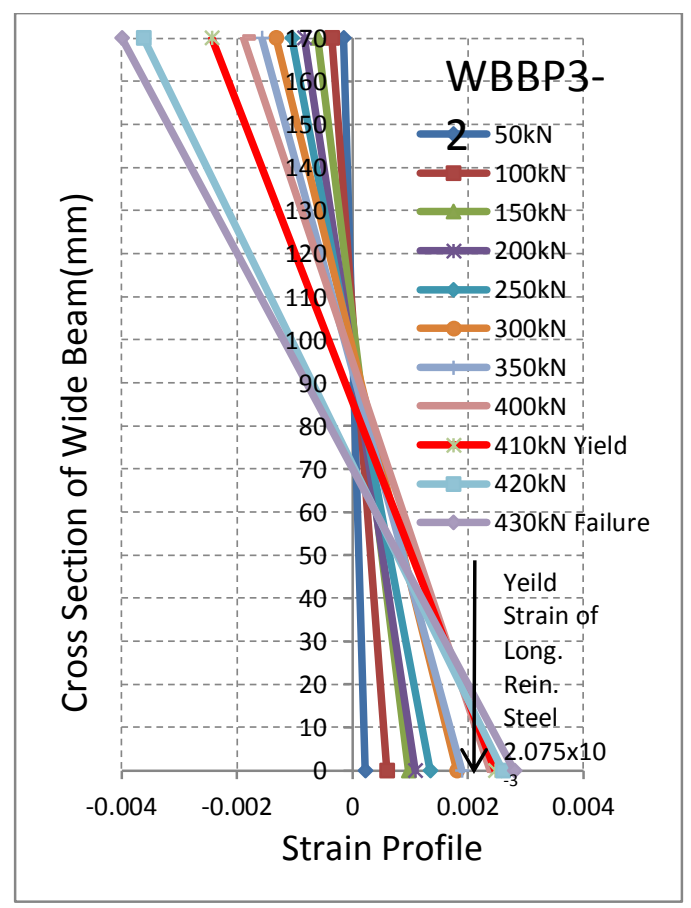

Figure 6: Strain profile of WBBP3-2 specimen face of specimens) is increased at yield and ultimate loads by $27 \%$ and $35 \%$ respectively for the specimens WBBP3-2 compared with WBBP3-1 specimen but it decreased by $4.4 \%$ and $3.7 \%$ respectively for WBBP3-3. The strain profile of four specimens is shown in Figure 4, 5, 6 and 7.

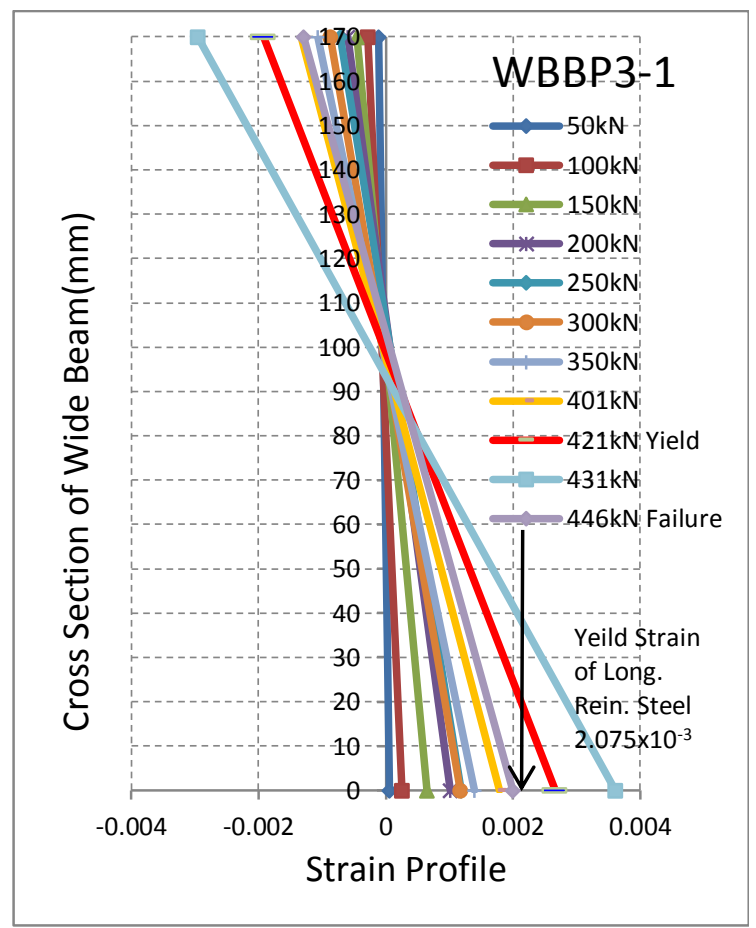

Figure 5: Strain profile of WBBP3-1 specimen

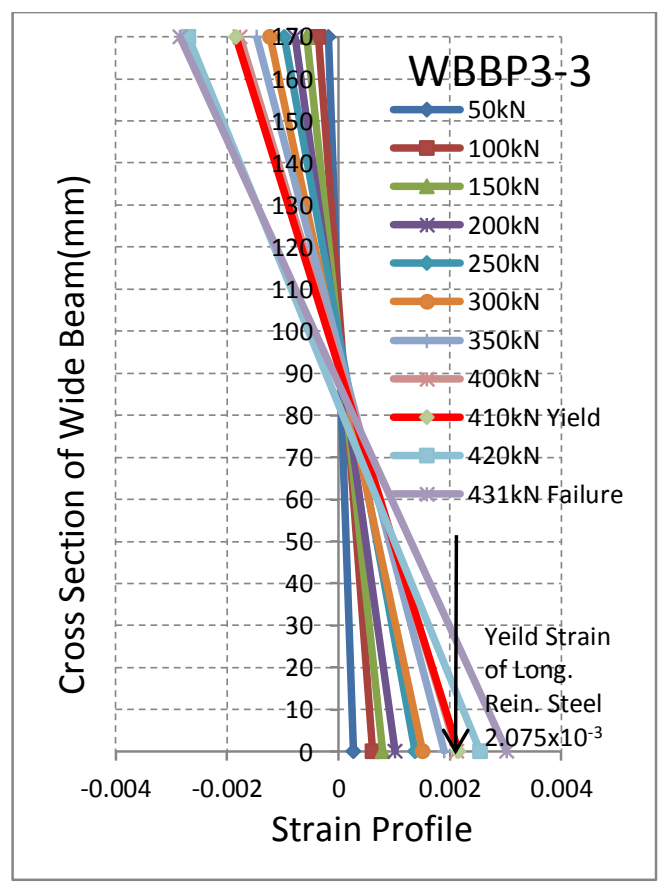

Figure (7): Strain profile of WBBP3-3 specimen 


\subsection{Strain Characteristics in Exterior and Interior Legs of Shear Steel Plate}

Table 3 shows the values of strain in exterior and interior legs of shear steel plate at yield and ultimate load that were obtained from strain gauge connected to data logger.

\subsection{1- Strain in Exterior Leg of Shear Steel Plate}

It can be seen from Table 4 that the strain exterior leg of shear steel plate is decreased by $28 \%$ and $6 \%$ for WBBP3-1 and WBBP3-2 respectively in comparison with WBBS at yield load, but it was increase by $383 \%$ for WBBP3-3. At ultimate load it is decreased by $17 \%$ and $5 \%$ for the specimensWBBP3-1 and WBBP3-2, but it was increased by $517 \%$ for WBBP3-3 as a result of sudden shear failure. By increasing the spacing of shear steel plate by $33 \%$ and $100 \%$, it can be seen that the stain in specimens WBBP3-2 and WBBP3-3 is more than strain of WBBP3-1 by $35 \%$, and $573 \%$ respectively (at yield) and by $14 \%$ and $643 \%$ respectively (at ultimate). This increasing in strain exterior leg of shear steel plate at yield and ultimate load stages may be due to decreasing the number of shear steel plate and increasing of spacing and decreasing of concrete shear component as a result of the presence of bubbles.

\subsection{2- Strain in Interior Leg of Shear Steel Plate}

It can be seen from Table 4 that the strain of interior leg of shear steel plate is increased by $47 \%, 61 \%$ and $418 \%$ for WBBP3-1, WBBP3-2 and WBBP3-3 respectively in comparison with WBBS at yield load, and by $84 \%, 133 \%$ and $474 \%$ at ultimate load. The high increasing in interior leg strain for WBBP3-3 specimen is a result of sudden shear failure. By increasing the spacing of shear steel plate by $33 \%$ and $100 \%$, it can be seen that the stain in specimens WBBP3-2 and WBBP3-3 is more than strain of WBBP3-1 by $10 \%$, and $253 \%$ respectively (in yield) and by $26 \%$ and $213 \%$ respectively (in ultimate). This increasing in strain interior leg of shear steel plate at yield and ultimate load stage may be due to decreasing the number of shear steel plate and increasing of spacing and decreasing of concrete shear component as a result of bubbles present. The main notice was observed that the difference between the stain in exterior and interior legs. It is clear that the strain in interior leg is more than strain in exterior leg about $41 \%, 189 \%, 142 \%$ and $52 \%$ for WBBS, WBBP3-1, WBBP3-2 and WBBP3-3 respectively at yield load, and about $35 \%$, $199 \%, 231 \%$ and $25 \%$ respectively at ultimate load.

Table 4 Strain characteristics in shear steel plate (Exterior and Interior legs) of specimens

\begin{tabular}{|c|c|c|c|c|c|c|c|c|}
\hline \multirow[b]{2}{*}{$\begin{array}{l}\text { Beam } \\
\text { Specimens }\end{array}$} & \multicolumn{4}{|c|}{$\begin{array}{l}\text { Shear Reinforcement } \\
\text { Plate(exterior leg) }\end{array}$} & \multicolumn{4}{|c|}{$\begin{array}{l}\text { Shear Reinforcement } \\
\text { Plate(interior leg) }\end{array}$} \\
\hline & $\begin{array}{l}\varepsilon_{y} \\
\mathrm{x} 10^{-3}\end{array}$ & $\begin{array}{l}\% \text { diff. } \\
\text { of }^{\varepsilon_{y}}\end{array}$ & $\begin{array}{c}\mathcal{E}_{u} \\
\mathrm{x} 10^{-3}\end{array}$ & $\begin{array}{l}\% \text { diff. } \\
\text { of } \varepsilon_{u}\end{array}$ & $\begin{array}{c}\varepsilon_{y} \\
\times 10^{-3}\end{array}$ & $\begin{array}{l}\% \text { diff. } \\
\text { of } \varepsilon_{y}\end{array}$ & $\begin{array}{l}\varepsilon_{u} \\
\times 10^{-3}\end{array}$ & $\begin{array}{l}\% \\
\text { diff. } \\
\text { of } \\
\varepsilon_{u}\end{array}$ \\
\hline WBBS & 0.752 & --- & 0.853 & --- & 1.06 & -- & 1.15 & --- \\
\hline WBBP3-1 & 0.539 & $-28 \%$ & 0.709 & $-17 \%$ & 1.56 & $47 \%$ & 2.12 & $84 \%$ \\
\hline WBBP3-2 & 0.706 & $-6 \%$ & 0.810 & $-5 \%$ & 1.71 & $61 \%$ & 2.68 & $133 \%$ \\
\hline WBBP3-3 & 3.630 & $383 \%$ & 5.270 & $517 \%$ & 5.50 & $418 \%$ & 6.60 & $474 \%$ \\
\hline
\end{tabular}

1. In all specimens the experimental strain at yield and ultimate it is reached to the nominal yield and ultimate strain of stirrups or plate except WBBS specimen (at yield).

\section{5- Comparison between the Yield and Ultimate Strain (Nominal and Experimental) of Steel Plate}

Table 5 explains a comparison of the yield and ultimate nominal strain and experimental strain in shear reinforcement (stirrups) and shear steel plate for interior leg. It can be seen that:
2. The experimental strain at yield load is less than nominal strain by $57 \%$ for the specimen WBBS while the experimental strain at yield load and it is more than nominal strain by $48 \% 63 \%$ and $524 \%$ for 
the specimen WBBP3-1, WBBP3-2 and WBBP3-3 respectively.

3. The experimental strain at ultimate load is more than nominal strain by $70 \%$ for the specimen WBBS while the experimental strain at ultimate is more than nominal strain by $41 \% 78 \%$ and $440 \%$ for the specimen WBBP3-1, WBBP3-2 and WBBP3-3 respectively.

\section{6- Crack Pattern}

The tested beams at different stages of loading are shown in details in Figure 8 and Plate 1. The bearing numbers inside the circles represent the sequence of formation of the cracks, while the numbers shown under the beams between those representing the sequence are the cracks spacing. The sign $(*)$ represents to the first crack width appeared.

From these figures the following conclusions can be drawn:

1. Due to the constant moment applied within the middle third of the beam the sequence of formation of cracking was random, and cracks grew upward with the increase of the applied load.
2. Cracks forming within the middle third of the beams were generally vertical due to the pure moment applied on this part of the beam. Outside this zone the cracks became inclined due to the presence of shearing forces in addition to the moment.

The specimen WBP3-3 was failed under high shear action. When the diagonal crack occurs, there must be a redistribution of internal forces at the cracked section. And when the beam has no web reinforcement, the external shear resisted by the concrete web must be redistributed partly to the tensile reinforcement through dowel action but mainly to the compression zone of concrete. The redistribution must take place by the web reinforcement. For the WBBP3-3 the failure was immediately happen, it is possible interpreted that the member does not accept any redistribution when the diagonal crack forms. In this case, the web reinforcement will yield immediately and the compression zone will be destroyed immediately [9]. The main difference between crack pattern of bubbled specimens is related to the shape of shear cracks. The shear cracks are tack the inclined and take a polyline around the bubbles.

Table 5 Strain characteristics in shear steel interior plate leg

\begin{tabular}{|c|c|c|c|c|c|c|c|c|}
\hline Specimens & $\begin{array}{l}\mathbf{f}_{\mathbf{y}} \\
(\mathbf{M P a})\end{array}$ & $\begin{array}{l}\mathbf{f}_{\mathbf{u}} \\
\text { (MPa) }\end{array}$ & $\begin{array}{l}\varepsilon_{y} \\
\mathrm{x} 10^{-3}\end{array}$ & $\begin{array}{l}\varepsilon_{y} \\
\text { x } 10^{-3} \\
\text { Experimental }\end{array}$ & $\frac{\varepsilon_{y} \exp }{\varepsilon_{y}}$ & $\begin{array}{l}\mathcal{E}_{u} \\
\mathrm{x} 10^{-3}\end{array}$ & $\begin{array}{l}\varepsilon_{u} \\
\times 10^{-3} \\
\text { Experimental }\end{array}$ & $\frac{\varepsilon_{u} \exp }{\varepsilon_{u}}$ \\
\hline "WBBS & 397 & (2685 & $\begin{array}{l}1.985 \\
\end{array}$ & 1.06 & 0.53 & 1.15 & 1.96 & $\bar{~} 1.70$ \\
\hline WBBP3-1 & 210 & 300 & 1.050 & 1.56 & 1.48 & 1.50 & 2.12 & 1.41 \\
\hline WBBP3-2 & 210 & 300 & 1.050 & 1.71 & 1.63 & 1.50 & 2.68 & 1.78 \\
\hline WBBP3-3 & 210 & 300 & 1.050 & 5.50 & 5.24 & 1.50 & 6.60 & 4.40 \\
\hline
\end{tabular}


Table 6 First crack width, number and spacing of shear cracks for specimens

\begin{tabular}{|c|c|c|c|c|c|c|c|c|c|}
\hline \multirow{2}{*}{$\begin{array}{l}\text { Beam } \\
\text { Specimens }\end{array}$} & \multicolumn{2}{|c|}{$\begin{array}{l}1^{\text {st }} \quad \text { Crack } \\
\text { Cracking }\end{array}$} & \multicolumn{2}{|c|}{$\begin{array}{lll}1^{\text {st }} & \text { Crack at } \\
\text { Yield } & & \end{array}$} & \multicolumn{2}{|c|}{ No. of Cracks } & \multicolumn{3}{|c|}{$\begin{array}{lll}\text { Spacing } & \text { of } & \text { Shear } \\
\text { Cracks }(m m) & & \end{array}$} \\
\hline & $\begin{array}{l}\text { Load } \\
(\mathrm{kN})\end{array}$ & $\begin{array}{l}\text { Width } \\
(\mathrm{mm})\end{array}$ & $\begin{array}{l}\text { Load } \\
(\mathrm{kN})\end{array}$ & $\begin{array}{l}\text { Width } \\
(\mathbf{m m})\end{array}$ & flexural & Shear & $\begin{array}{l}\text { Min. } \\
\text { Spacing }\end{array}$ & $\begin{array}{l}\text { Max. } \\
\text { Spacing }\end{array}$ & $\begin{array}{l}\text { Average } \\
\text { Spacing }\end{array}$ \\
\hline WBBS & 40 & 0.005 & 361 & 0.20 & 6 & 11 & 50 & 100 & 75 \\
\hline WBBP3-1 & 60 & 0.005 & 421 & 0.26 & 4 & 9 & 50 & 140 & 100 \\
\hline WBBP3-2 & 50 & 0.005 & 410 & 0.20 & 5 & 10 & 40 & 160 & 95 \\
\hline WBBP3-3 & 40 & 0.005 & 410 & 0.18 & 5 & 11 & 50 & 140 & 122 \\
\hline
\end{tabular}
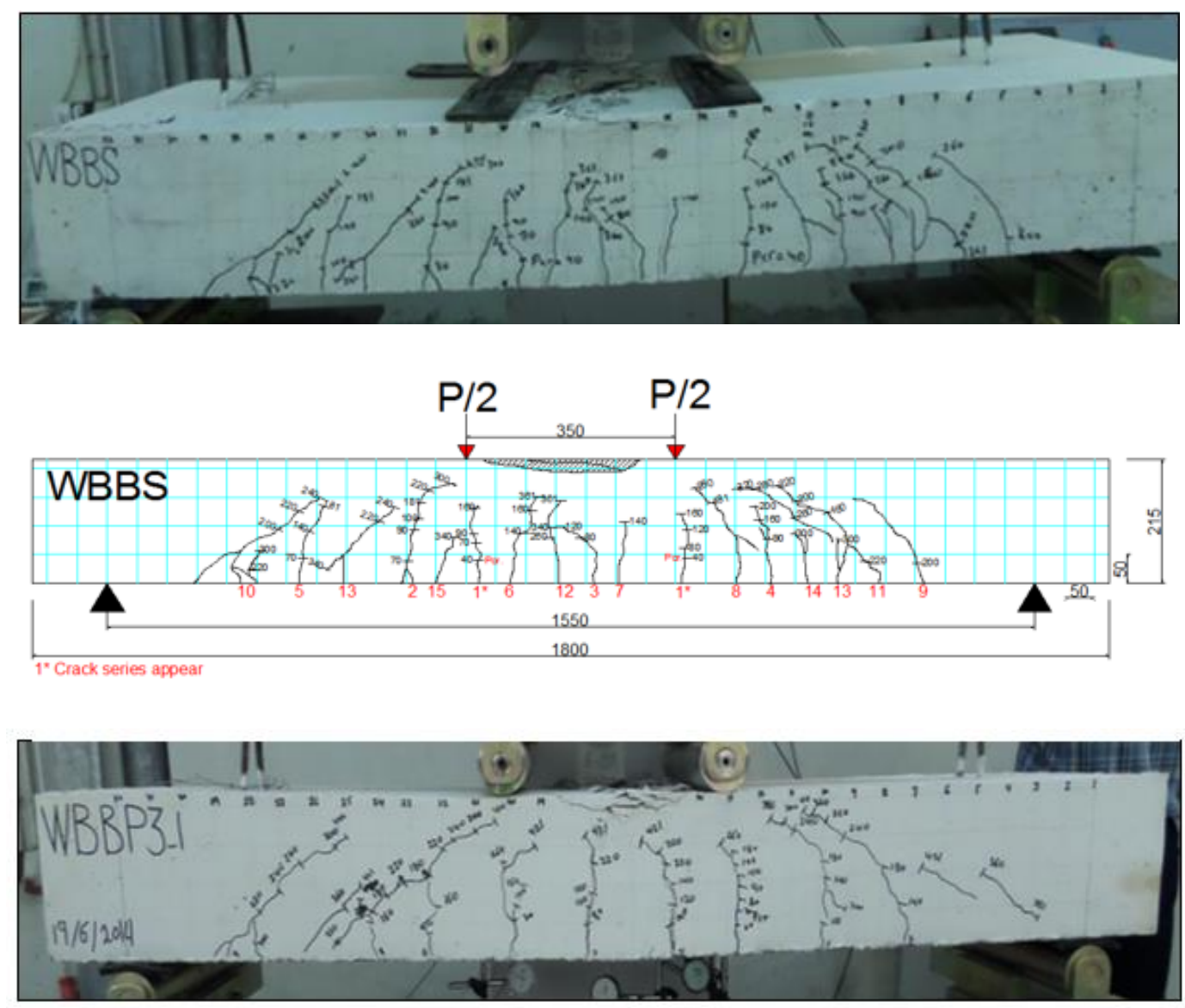

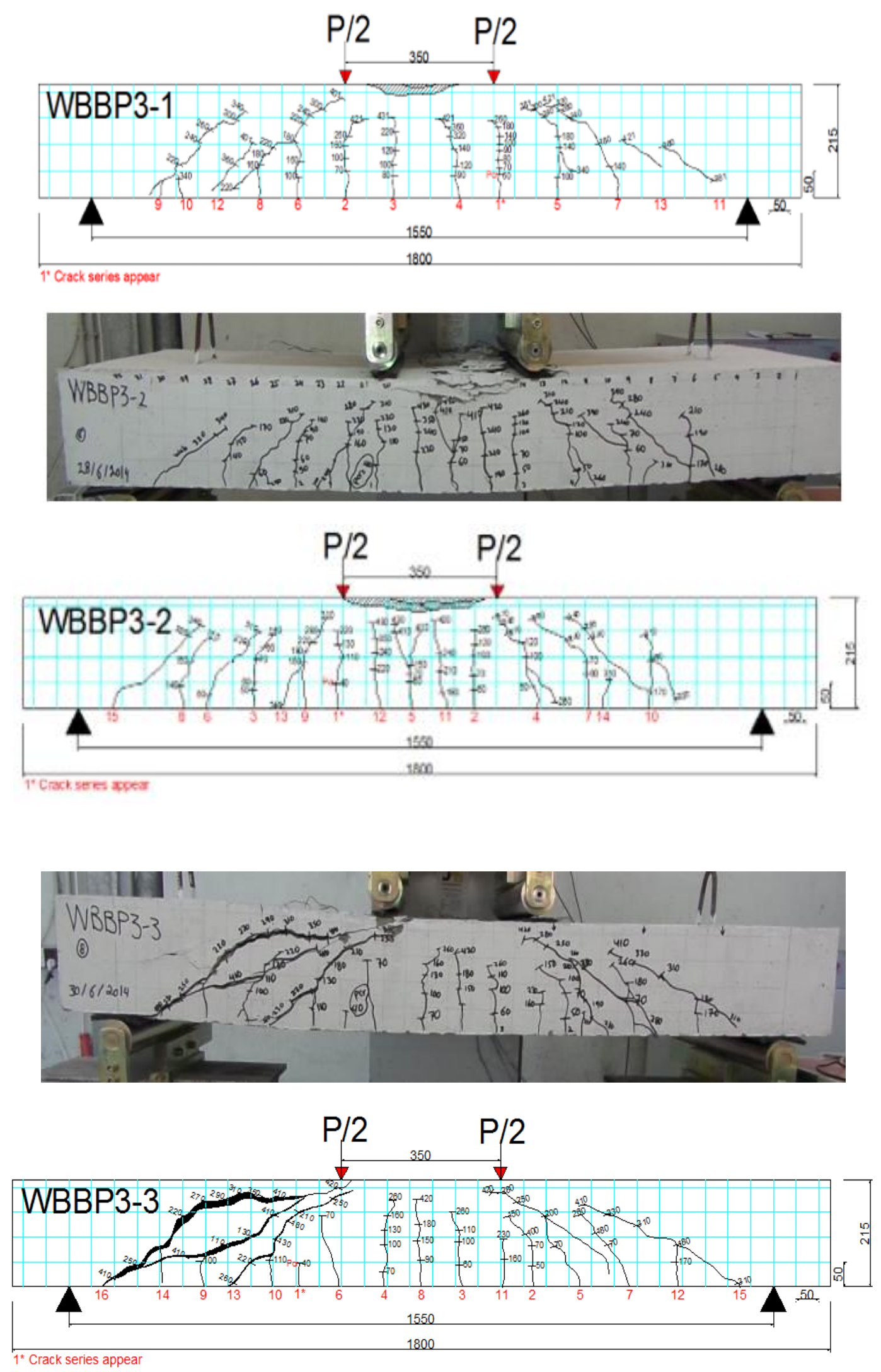

Plate 1 and Figure 8 


\section{7- The First Crack Width}

It can be seen from Table 6, the crack width of the first crack at cracking and yield load. The first crack appeared randomly within the middle third of the span (zone of maximum moment), was not necessarily the widest one. The first crack width at cracking load is equally in all specimens as a result of the same properties of concrete and longitudinal reinforcing. Also the first crack width at yield load is close in specimens except increasing by $30 \%$ for WBBP3-1 compare with WBBS specimen as a result of increasing the yield load.
$0.12 \mathrm{~mm}$ and $0.21 \mathrm{~mm}$ on average. The predicted crack width at service and yield loads of wide beams computing by ACI $318 \mathrm{M}$ 14 [1] and EC 2 [2] codes (0.21 and 0.33) mm and $(0.12$ and 0.19$) \mathrm{mm}$ on average respectively. So it can be seen that:

1. The experimental crack width at service and yield load was more than predicted crack width computed by ACI $318 \mathrm{M}-14$ [1] by $68 \%$ and $56 \%$ respectively.

2. The experimental crack width at service was close to predicted crack width computed by EC 2 [2] but it was less than the experimental crack width by $11 \%$ at yield load.

Table 7 First crack width, number and spacing of shear cracks for specimens

\begin{tabular}{|c|c|c|c|c|c|c|}
\hline \multirow{3}{*}{$\begin{array}{l}\text { Beam } \\
\text { Specimens }\end{array}$} & \multicolumn{6}{|c|}{ Crack Width (mm) } \\
\hline & \multicolumn{2}{|l|}{ Experimental } & \multicolumn{2}{|c|}{ According ACI 318M-14 } & \multicolumn{2}{|c|}{ According EC 2} \\
\hline & $\begin{array}{l}\text { At } \text { Service } \\
\text { load }\end{array}$ & $\begin{array}{ll}\text { At } & \text { Yield } \\
\text { load }\end{array}$ & $\begin{array}{l}\text { At } \text { Service } \\
\text { load }\end{array}$ & $\begin{array}{ll}\text { At } & \text { Yield } \\
\text { load }\end{array}$ & $\begin{array}{l}\text { At } \text { Service } \\
\text { load }\end{array}$ & $\begin{array}{ll}\begin{array}{l}\text { At } \\
\text { load }\end{array} & \text { Yield } \\
\end{array}$ \\
\hline WBBS & 0.11 & 0.20 & 0.188 & 0.327 & 0.109 & 0.190 \\
\hline WBBP3-1 & 0.16 & 0.26 & 0.221 & 0.327 & 0.128 & 0.190 \\
\hline WBBP3-2 & 0.12 & 0.20 & 0.215 & 0.327 & 0.125 & 0.190 \\
\hline WBBP3-3 & 0.12 & 0.18 & 0.215 & 0.327 & 0.125 & 0.190 \\
\hline
\end{tabular}

\section{8- Shear Cracks Spacing}

Concerning the number of shear cracks, it can be seen from Table 6 that the number of shear cracks was close except decreasing by $18 \%$ for WBBP3-1 compare with WBBS specimen. Minimum spacing of shear cracks was close in specimens with $50 \mathrm{~mm}$, but the maximum and average spacing was increased by $40 \%, 60 \%$ and $40 \%$ (maximum) and by $33 \%, 26 \%$ and $63 \%$ (average) for WBBP3-1, WBBP3-2 and WBBP3-3 compare with WBBS. By increasing the spacing of shear steel plate by $33 \%, 100 \%$, the number of shear cracks was increased by $11 \%$ and $22 \%$ respectively.

\section{9- Comparison the First Crack width Computing by ACI 318M-14 [1] and EC 2 [2] Codes}

It can be seen from Table 6, the experimental crack width of the first crack at service and yield load comparing with predicted first crack width according to the ACI 318M-14 [1] and EC 2 [2] codes. The experimental crack width of all specimens at service and yield load was
3. From (1) and (2) above EC 2 [2] code was more conservative than ACI 318M-14 [1].

\subsection{0- Comparison the Crack Spacing Computing by ACI 318M-14 [1] and EC 2 [2] Codes}

Table 8 shows the measured and predicted values of crack spacing according to BS811085 [10] and EC 2 [2] only because no such formulas were proposed in other codes of design [1]. In BS8110-85[ 10], the average crack spacing approximately equal $1.67(\mathrm{~h}-\mathrm{x})$ for primary cracks, in this method the height of neutral axis determines the spacing of cracks. It can be seen from Table 8 that:

(1) The predicted mean crack spacing according to BS8110-85 [10] ranged between $215 \mathrm{~mm}$ and $220 \mathrm{~mm}$ for all four wide beams tested. And the experimental average crack spacing ranged $76 \mathrm{~mm}$ to $105 \mathrm{~mm}$. By comparing the values obtained experimentally and those predicted using BS8110-85 [10] formula, it can be seen that the predicted values more than experimental values by $140 \%$ on average. 
(2) The predicted minimum and maximum crack spacing according to EC 2 [2], $92 \mathrm{~mm}$ and $160 \mathrm{~mm}$ respectively all four wide beams tested. From Table 7 it can be seen that the EC 2 [2] formula did not consider the concrete compressive strength, thus for all the investigated specimens, the crack spacing were the same for beams with the identical reinforcement. This was noted that situation obtained experimentally; the minimum and maximum crack spacing was bounded by (40mm to $50 \mathrm{~mm})$, and by $(120 \mathrm{~mm}$ and $160 \mathrm{~mm})$ respectively. By comparing the values obtained experimentally and those predicted using EC $2^{(2)}$ formula, it can be seen that it can be seen that the predicted values of minimum and maximum spacing is more than experimental values by $104 \%$ and $12 \%$ on average.

A modification in the formulas proposed by BS8110-85 [10] and EC 2 [2] are needed to consider the spacing of shear reinforcement.

\subsection{1- Comparison between the Weights of Specimens}

It can be seen from Table 1 that using the shear steel plate was reduced the weight by $2.3 \%$, $2.7 \%$ and $3.1 \%$ for specimens WBBP3-1, WBBP3-2 and WBBP3-3. It is clear that using shear steel plate is reduced the weight of specimens by $2.7 \%$. But the weight was

\section{Conclusions and Recommendations}

1. Shear steel plate is a good alternative for replacing stirrups (as web reinforcement) in bubbled wide beams and gives increasing at yield and ultimate load with $17 \%$ and $18 \%$ of yield and ultimate load respectively.

2. Replacing stirrups by shear steel plate in bubbled wide beams gives a reduction in deflection at yield and ultimate load with $8 \%$ and $12 \%$ of yield and ultimate load respectively.

3. Replacing stirrups by shear steel plate in bubbled wide beams decrease the strain in longitudinal reinforcement by $10 \%$ and $24 \%$ of yield and ultimate load respectively.

4. Using shear steel plate, reduce the stain in exterior leg by $28 \%$ compared with stirrups, although the yield strength of shear steel plate is less than stirrups yield strength by $47 \%$.

5. Using the shear steel plate instead of stirrups reduced the total weight of wide beams by $2.7 \%$. Also using the bubbles in specimens was displaced $4.7 \%$ from the total weight of specimen.

6. By using steel shear plate of $3 \mathrm{~mm}$ thickness, with spacing between steel

Table 8 Comparing of number of cracks and experimental crack spacing with crack spacing computing by of BS $8110^{(10)}$ and EC $2^{(2)}$ cods

\begin{tabular}{|c|c|c|c|c|c|c|c|c|}
\hline \multirow{3}{*}{$\begin{array}{l}\text { Beam } \\
\text { Specimens }\end{array}$} & \multirow{2}{*}{\multicolumn{2}{|c|}{ No. of Cracks }} & \multicolumn{6}{|c|}{ Spacing of Cracks (mm) } \\
\hline & & & \multicolumn{3}{|c|}{ Experimental } & \multirow{2}{*}{$\begin{array}{l}\text { According } \\
\text { BS } 8110 \\
\text { Mean } \\
\text { Spacing }\end{array}$} & \multicolumn{2}{|c|}{ According EC 2} \\
\hline & flexural & Shear & $\begin{array}{l}\text { Min. } \\
\text { Spacing }\end{array}$ & $\begin{array}{l}\text { Max. } \\
\text { Spacing }\end{array}$ & $\begin{array}{l}\text { Average } \\
\text { Spacing }\end{array}$ & & $\begin{array}{l}\text { Min. } \\
\text { Spacing }\end{array}$ & $\begin{array}{l}\text { Max. } \\
\text { Spacing }\end{array}$ \\
\hline WBBS & 6 & 11 & 40 & 120 & 76 & 219 & 91.8 & 160 \\
\hline WBBP3-1 & 4 & 9 & 50 & 150 & 105 & 220 & 91.8 & 160 \\
\hline WBBP3-2 & 5 & 10 & 40 & 160 & 93 & 215 & 91.8 & 160 \\
\hline WBBP3-3 & 5 & 11 & 50 & 140 & 93 & 216 & 91.8 & 160 \\
\hline
\end{tabular}

displaced by bubbles was around $4.7 \%$ from

the total weight of sold beam (without bubbles). plates of 125,166 and $250 \mathrm{~mm}$ (increasing the spacing by $33 \%$ and $100 \%$ ), and it can be notified:

- The deflection at yield was increased by $37 \%$ and $20 \%$ respectively. 
- $\quad$ The yield and ultimate loads are reduced by $3 \%$ and $4 \%$ respectively.

- The strain in longitudinal reinforcing was decreased by $7.7 \%$ at yield and by $22 \%$ and $16 \%$ respectively at ultimate load.

- The strain in exterior leg was increased by $35 \%$ and $573 \%$ respectively at yield load and by $14 \%$ and $643 \%$ respectively for the interior legs.

- At yield: the strain in interior legs is more than the strain in exterior leg by $189 \%$, $142 \%$ and $52 \%$.

- The number of shear cracks is increased by $11 \%$ and $22 \%$ respectively.

7. The predicted deflection of wide bubbled beams as per ACI 318-14 [1] and EC 2 [2] codes were less than the experimental deflection by $26 \%$ and $30 \%$ on average respectively.

8. EC 2 [2] code was more conservative than ACI $318 \mathrm{M}-14^{(1)}$ to predicted the crack width.

9. A modification in the formulas proposed by BS8110-85 [10] and EC 2 [2] are needed to consider the spacing of shear cracks.

\section{References:}

[1] ACI Committee 318M-14, Building Code Requirements for Structural Concrete and Commentary, American Concrete Institute, Farmington Hills, MI, (2014), pp 465.

[2] Eurocode 2, Design of Concrete Structures-Part 1-1: General Rules and Rules for Buildings (EN1992-1-1), European Committee for Standardization, Brussels, Belgium, Dec. (2004), pp225.

[3] Adam S. Lubell, Edward G. Sherwood, Evan C. Bentz, and Michael P. Collins (2006), One way shear strength of thick slabs and wide beams, ACI Structural Journal, Vol. 103, no. 6, Nov. - Dec. 2006, pp. 794-802.

[4] Adam S. Lubell, Evan C. Bentz, and Michael P. Collins (2009), Shear reinforcement spacing in wide members,
ACI Structural Journal, vol. 106, no. 2, March - April 2009, pp. 205-214.

[5] ACI Committee 318 (2011): Building code requirements for structural concrete (ACI 318-11) and commentary (318R-11). Farmington Hills: American Concrete Institute.

[6] Mohamed M. Hanafy, Hatem M. Mohamed and Nabil A.B. Yehia (2012), On the Contribution of Shear Reinforcement in Shear Strength of Shallow Wide Beams, Life Science Journal Vol. 9, no. 3, 2012, pp. 484-498.

[7] Amer M. Ibrahim, Wissam D. Salman, Qusay W. Ahmed, (2015), Effect of steel plates on shear strength of wide reinforced concrete beams, Journal of Engineering and Development, Vol.19, No.3, May. (2015), ISSN 1813- 7822.

[8] Ferdinand P. Beer E. Russell Johnston, Jr. John T. De Wolf, (2009), Mechanics of Materials, Lecture Notes: J. Walt Oler Texas Tech University.

[9] ACI-ASCE Committee 326, shear and diagonal Tension

[10] Structural Use of Concrete -Part 2 Code of Practice for Design and Construction (8110), (1985), British Standard Institution, London. 